\title{
FROM PERSONAL COMPUTER TO FACEBOOK: INFORMATION AND COMMUNICATION TECHNOLOGY AND ENGLISH WRITING RESEARCH
}

\author{
I Gusti Ngurah Agung Wijaya Mahardika \\ Institut Hindu Dharma Negeri Denpasar \\ wijayamahardika@gmail.com
}

\begin{abstract}
This paper describes several research conducted in the area of Information and Communication Technology and English Writing. The aim of this paper is to paint a picture about the kind of technology used in writing which caught the attention of researchers. It covers the trend of ICT utilization in English writing from 1990s to date, as well as delineating the future research areas in this field. It covers the research on the use of Word Processor, Blog, and Facebook in English writing teaching and research.

As described herein, the use of technology especially ICT goes hand in hand with the development of humanity including in the field of education. In English writing the future will only see more pervasive and intensive use of ICT in education including in English writing classes.
\end{abstract}

Key words: ICT, English Writing, Blog, Facebook.

\section{INTRODUCTION}

The advancement of Information and Communication Technology has brought a dramatic shift in education, including in English language teaching. The involvement of ICT in English Language Teaching (ELT) has started from the Computer Assisted Language Learning of the $80 \mathrm{~s}$ to the latest introduction of mobile-based learning, Augmented Reality and Educational Games into ELT (Dudeney \& Hockly, 2012). Bax (2003) divided the early integration of ICT with ELT, which he termed as Computer Assisted Language Learning (CALL), to have happened in three stages. Bax offered his definition as an alternative of Warschauer and Healey's division of CALL (Warschauer \& Healey, 1998). The first stage was the Restricted Stage with the emphasis on basic interaction and the use of word processor with interaction between learners and content. The Second stage the Open stage as termed by Bax emphasis on the sophisticated interaction between the learner and computer. The computer provides the stimulus for the user. The third stage of the CALL was termed integrated phase, this stage is defined by the development and usage of multimedia and early internet access. Said access plays vital role as in the integrative implementation of call in ELT. After the era of personal computer, the establishment of WEB 1.0 by Tim Burners-Lee in 1989 started a brand new era of learning (Aghaei, Nematbakhsh, \& Farsani, 2012).

Web 1.0 is the first generation of the web which according to Berners-Lee, could be considered the read-only web. It 
started as a place to put business information the limited user. People can only come and search for information. This was then followed by we 2.0, it enables people to interact in social interaction. Due to the ability of the user to share information by themselves, the web 2.0 is also called the read-write web. Web 3.0 or semantic web was aimed at decreasing human decision making and transferring such load to the computer by providing machine-readable contents. This way, the user can use the web by giving only limited command to the system, and the system will respond. The development of the web has also affected the teaching of English writing, since teachers all over the world view the web and web-related tools as valuable learning tools. This paper attempts to present a small review on the development of ICT and its effect on English writing teaching as documented in research publications as well as the reviewer's research plan as the result of the review. This paper is divided into two parts, the first part is the review of previous research in ICT and Writing. The second part discusses the area of research on ICT and Writing which have not been conclusively studied as well as a possible area for future research.

\section{DISCUSSION}

\subsection{ICT AND WRITING IN 1990-2000: THE WORD PROCESSOR}

ICT has been used in all skills of English, including in relation with teaching writing skill. The first computer technology used in writing was, naturally, the personal computer and the word processor software. The public sale of the first microcomputer in the 70s has changed the way people write which in turn changed the way English teacher teach writing (Hawisher \& Selfe, 1991). MacArthur (1988) described the word processor as having several important ways that may influence the writing process. First, word processors permit flexible editing of text. Second, the visibility of the monitor and the use of a keyboard make writing more public. Third, they provide neat, printed copy. Fourth, they change the physical process of producing text, replacing handwriting with typing. Finally, word processors are complex tools that require some learning. MacArthur concludes that computers in general are beneficial to writing process for they provide a wide range of opportunities for improving the teaching of writing. He also notes that word processor changed the physical process of writing from handwriting to typing, thus allowing quick and convenient revision (MacArthur, 1988: 541). The change in physical process of writing facilitated by the word processor made the improvement that would have been difficult on paper, become more convenient on word processor. By removing the difficulties of the mechanical process of text revision user can focus on making the revision they want, thus word processor user might produce longer and better text (BangertDrowns, 1993).

This opinion was corroborated by the results of Sullivan \& Pratt' research which compared the writing quality between students taught with computer and students taught in conventional oral classroom. The research found that the students in computer-assisted classroom demonstrated more interest in 
discussion, since the discussion was held over writtenchat software, students had more practice in writing and had more time to compose their responses compared to the students in oral classroom. Students in computer-assisted classroom also showed significant gain compared to the students in oral classroom (Sullivan \& Pratt, 1996). There was significant change between the pre and post writing score within each class. The students in the two classes did not differ significantly at the beginning of the test, but the means score of the oral class decrease significantly, meanwhile the mean score of the computer-assisted class increased significantly. This result showed that the use of computer helps the students in producing better writing.

The study also showed that students of the computer-assisted class involved more actively in the classroom discussion which was held though written electronic chat. The data showed that the computer-assisted class had $100 \%$ participation and the oral class only had $50 \%$ participation. On the other hand, teacher had $65 \%$ contribution to the turn-taking in oral class compare to only $15 \%$ contribution in Computer Assisted class. This result signifies that the computer-assisted class is more student-centered than the oral class.

One interesting aspect of the research is that the students showed no change of attitude towards writing, despite the fact that they have positive attitude towards writing with computer or word processing. This means that the different modes of writing do not automatically increase the students' positive attitude towards writing. This phenomenon, i.e the increase of students writing score as well as the students' attitude towards writing were also noted by several researchers (Bangert-Drowns, 1993; Cooper and Selfe, 1990; Sullivan, 1993) other researchers also found that along with the increase of the writing score, students also had more positive attitudes to writing with computer but not with writing per se (RobinsonStaveley \& Cooper, 1990). In this particular study, the researcher argues that the use of a computer on an ongoing basis in a writing course has a positive effect on attitudes toward computers and has no effect on attitudes toward the course or toward writing.

There are several things that can be summarized from the research on the use of ICT and writing in the 90s. the first is that all the research shows the benefit of using word processor in writing, and that writing with computer of word processor resulted in superior writings. The students were more motivated in writing, has positive attitude towards writing with computer, but no different attitude towards writing per se. this last part becomes something which is very interesting, and will need to be studied further.

\subsection{ICT AND WRITING IN 2000-2010: THE BLOGOSPHERE}

The year 2000 was an important point in the development of ICT, after the Y2K scare had subsided, the internet flourished as the number of new interconnected software and websites mushroomed. The use of ICT in English writing also increased and extensifies. Moving from word processor and personal computer to more web-based writing. The research on ICT and Writing 
conducted between 2001-2010 mainly focused on Blog. Blog is short for 'Web $\log ^{\prime}$ it is best described as an online journal (Drexler, Dawson, \& Ferdig, 2007) Goldwin define blog as a webbased space for writing where all the writing and editing of information is managed through a web browser and is immediately and publicly available on the Internet (Godwin-Jones, 2003). To summarize, blog is a form of online journal or diary, with comment section, where the readers can comment and give feedback to the writer. Thus blog is quite interactive in a way that it enables the writer and the readers to interact on a piece of writing which is termed as an entry.

Three types of blogs have been described for use in English writing class by Campbell (2003): the tutor blog; the learner blog; and the class blog. The tutor blog is run by the tutor for the learner, and its purpose is to give reading practice to the learners, promote exploration of English websites, encourage online exchange by use of comment buttons, provide class or syllabus information, and serve as a resource of links for selfstudy. Learner blogs are run by individual learners themselves. Learner blogs are best suited for English reading and writing classes. The class blog is the result of the collaborative effort of an entire class. It can be used for posting messages, images, and links related to classroom discussion topics in English. Class blogs could also be used as a virtual space for an international classroom language exchange (Campbell, 2003).

A study on collaborative blogging as a means to develop elementary expository writing skill was conducted 16 by Drexler, Dawson, \& Ferdig in 2007. The study examined the collaborative blogging between K-12 students and preservice teachers. The study aimed at investigating students' attitude towards writing, their motivation in writing, and the quality of their writing. The study found that Collaborative Blogging helped improve students' attitude towards writing. The result of the attitude survey showed an increase in students' positive response (denoting positive attitude towards writing) after the collaborative blogging. Researcher field notes and observation students' motivation to be prompted by the collaborative action instead of by the use of technology. The students exhibited great effort to write well to please their preservice counterpart. Students also exhibited disappointment when they have to move on to new activity because the students were really enjoying the learning process. The researcher state that considering that the students had used computer regularly the novelty of the blog had worn off. The students stated that it was the feedback that motivated them to strive. The study also found that collaborative blogging improved students' writing and supported development of related skills and knowledge. Quantity and quality of writing increased. In one respect, since this was a first attempt at a fiveparagraph essay, just completing the project constituted an improvement. Yet, there was also significant improvement in the writing quality of each paragraph as students progressed through the editing process with the preservice teachers. Editing is one of the most difficult steps in the writing process. 
Ducate and Lomicka (2008) conducted a year long study on the use of blog for students both from the point of view of the student as a reader and as a writer of a blog. The study was conducted in two major phase, the reading phase and the writing phase which was conducted in one semester each. In the writing phase, the students select a blog to be followed and then read the blog they selected. By the end of the semester, the researcher conducted a survey and found that over half of the students reported that they enjoyed reading the blog, most reported that it helped them to improve their reading skills and vocabulary in the target language, and they felt it slightly increased their knowledge of popular culture in the target culture.

In the second semester the students were instructed to set up their own blog and then post a piece of writing every week on teacher assigned topics that were related to the textbook topics. After posting, students wrote two comments in response to their classmates using a list of prescribed discourse strategies to encourage them to practice agreeing, disagreeing, complimenting, etc. and using the appropriate discourse strategies for each act. For extra credit, students could write personal postings whenever they wanted. At the end of the semester, the researcher found that Most students responded that they had a positive experience writing the blogs. They were able to learn from their peers and improve their vocabulary and writing. Due to this learning potential, students reported that they see blogs as having high academic value and would like to use blogs again in the future.
The result of the study mirrored the results from the study conducted by Sayed (2010). In his study, Sayed investigated the effect of blog-based peer feedback on students' persuasive writing. The design used was pre-test post-test control group experimental study where 20 students were randomly assigned to control or experimental group. The two months experiment resulted in the experimental group taught with blogbased peer review scored higher on their persuasive writing compared to the control group taught with face-to-face feedback. The study found that the blogbased peer review achieved greater impact compared to the face-to-face peer review. Sayed argued that the blog-based peer review subscribed to the Arabic and Islamic culture which view face-to-face review as being too direct, thus the blogbased peer review provided the facesaving environment which resulted in immense improvement of the students' writing (Sayed, 2010: 61). This is a very interesting cultural side of blog, which means that blog can be used in cultures which share the same values, and help the students with their writing in the same fashion.

To summarize, Blog is an effective technology to be used in improving students' writing, promote students' motivation and positive attitude towards writing and not just the technology used, and even helps students' whose cultural background may, to some extent, impede their effort to deliver effective feedback to their fellow students. As summarized by Zhang, blog facilitates students critical thinking skill through their interaction with their reader, and because the process of writing encourages students to 
read and write. Blog provides example and model from which the student can improve their writing. Blog affects the quality of the students' writing in many ways, for example, the awareness of real audience to their writing prompted students' to pay close attention to their writing. The quality of their writing also improved due to the feedback from their reader. Blog facilitates meaningful learning for the students through their exploration of information sources in preparation of their writing, and last but not least, blog gives the student a purpose for writing, because Students direct their own learning about topics important to them, while receiving feedback from others. Students take ownership in blogging activities by actively searching for information. (Zhang, 2009: 67-69). Blog's popularity as a writing aid continued well into the next decade, where even as late as 2018 researcher still actively investigate the effectiveness of blog amidst the general shift of attention to the latest contender, Facebook (Dizon and Thanyawatpokin. 2018).

\subsection{ICT AND WRITING IN 2010-2018: THE NEW CONTENDER,FACEBOOK}

The development of Facebook started in 2004 by Harvard student Mark Zuckerberg. The online social networking site provides users with a place to express themselves as well as showcasing things that they like. Soon, the site became an international hit and becomes the number one social networking site in the world. By June, 2011, more than 500 million active users were using Facebook to communicate, interact, and socialize with each other
(Shih, 2011). The popularity of Facebook along with its features which enable people to post messages, communicate via written chat, comment on other people posts, and even post longwritten piece in the form of a note made Facebook an ideal choice for online writing research subject. Teachers all over the world use Facebook to teach writing and researcher were also used Facebook as an aid in researching writing.

In 2011 Shih, conducted a study to investigate the effect of integrating Facebook and peer assessment with college English writing class instruction through a blended teaching approach. The study was conducted using mixed method design, started with quantitative study using pre-experimental pre-test and post-test design, followed with interview with the research subjects. The research concluded that the peer assessment of the writing as facilitated by Facebook has improve students' organization, grammar, writing content, vocabulary and their spelling accuracy. Similar results were also reported by Ibrahim, Saad, Tahir, \& Primsuwan (2018). Their study was conducted in Malaysia. The researchers contend that social media gave and edge for teacher in teaching because it promotes students' learning autonomy. They also posited that since the online discussion happen asynchronously, students will have ample time to develop their written responses before they participate in the discussion. This condition improves students' level of comfort in in the discussion and develop a keen sense of community (lbrahim, Saad, Tahir, \& Primsuwan 2018). 
The study was also conducted using mixed method design and it found that the students showed improvement in writing especially in grammar accuracy and vocabulary enhancement. The students also showed positive response towards the use of Facebook. Facebook was considered to be a great aid in fostering students' motivation and enhancing students' interest. Students' autonomy also increased since learning in a social environment put the control in the students' hands. Students also commented that Facebook poses less intimidating learning environment and more interactive. As the students were very familiar with Facebook, they could communicate and actively participate with the other members of the group, this in turn improved students' confidence as they see that they work together in a supportive manner with other students (Promnitz-Hayashi, 2011).

These results, however were inconclusive. There are other studies which showed that the use of Facebook does not change or improve students' achievement or writing ability. One of these studies is the study conducted by Altunkaya \& Topuzkanamis in 2018. The study was conducted on 96 students of Psychological Counseling and Guidance Department in the Faculty of Education in a state university located in western Turkey. The aim of the study was to investigate the effect of Facebook use on writing achievement, writing attitude, writing anxiety and writing self-efficacy of the students in the written expression course. The study used pre-test post-test quasi-experimental design with control group. Both the control and treatment group was taught using a book entitled
"Written Expression with Weekly Activities". However, the control group share and discuss their essay in conventional classroom, meanwhile the treatment group share and discuss their essay in a Facebook group named "ADU Turkish Written Expression" each week both groups were given similar assignment. By the end of the study the researcher that the achievement levels in the experimental group did not change, while those in the control group decreased. Writing self-efficacy increased in both control and experimental groups. Writing anxiety levels decreased in both control and experimental groups. The attitudes in the control group changed in the negative direction, while the writing attitudes in the experimental group remained unchanged (Altunkaya \& Topuzkanamis, 2018).

Another study conducted by Altakhaineh \& Al-Jallad in 2018, attempted to compare Twitter and Facebook for Arabic-speaking EFL learners' writing mechanics. The study was pre-test and post-test experimental design. The study measured the subjects English writing mechanics before and after the treatment to determine whether the use of Twitter helped the participants improve their knowledge of the mechanics of writing in English more than the use of Facebook or vice versa (Altakhaineh \& Al-Jallad, 2018). Both groups were given the assignments in form of writing description of a picture using Twitter or Facebook. The treatment was conducted for two weeks, with three activities per week. After the treatment a 100-word essay test was administrated to examine the participants' knowledge of the mechanics of L2 writing. The test 
measured the error made by the students in form of spelling, punctuation, grammar, and parts of speech. The results of the study showed that there are no statistically significant differences in L2 writing mechanics score between the treatment groups. The result suggests that at least statistically, that there was no relationship between the use of Twitter and Facebook to improve the mechanics of writing in English by the subjects. The researcher concluded that although both groups improved their language mechanics, as can be seen from the difference between each group's pre-test and post-test means, both Twitter and Facebook have similar effect on the students writing mechanics score.

Based on the results of the above studies we can conclude that the effect of Facebook on students writing is still debatable. Therefore, this opens up a new avenue of research for researcher in English Language Teaching especially in the area of using ICT in improving students writing. Further research should be done on this area, since Facebook is a very popular social networking site for the students and has good potential in helping students in learning English.

\subsection{ICT AND WRITING: TERRA INCOGNITA}

The advances in technology especially in Information and Communication Technology, have elevated writing skill into a prominent place in human communication. Writing is not just an ordinary skill to be taken for granted, but an essential one. Because through writing, one can communicate a variety of messages through any length of distance to both known and unknown readers. It is an important skill to master, whether it is done manually or with the help of technology such as computer or e-mail (Olshtain, 2001). Graham \& Perin voiced similar assessment of writing, theycontended that for young people, writing is not an option but a necessity, since writing and reading comprehension is the predictor of successful academic life as well as the basic requirement for participation in life and economy (Graham \& Perin, 2007). The advancement of technology especially the ICT has continuously facilitated the improvement of writing. From the invention of the Personal Computer to the era of social networking site and Web 3.0, English Teachers are continuously trying to use the latest technological advancement to facilitate students writing development.

The above studies paint a picture of progress, in which ICT plays vital part in English writing development. The results showed that ICT generally beneficial for students writing, such as improving students' grammatical accuracy, writing mechanics, motivation, writing skill, attitude towards ICT and so forth. So many research had been done in this field, yet there are still some areas which have not been fully studied or even have not been studied at all. The following part of this paper will discuss the area in ICT and writing which are still debated, not conclusively studied or even have not been studied at all.

The focus of the researches on ICT from 1990 to 2018 are on college level students. Since English writing is taught in all level of students, future researcher can shift the focus of their research to middle school or even elementary school 
level students. Students nowadays have been exposed to ICT and gadgets as well as the web from very early age, therefore there is no reason to stop researching the effect of ICT towards writing beyond college level students. The studies conducted so far were also conducted in small scale. It would be interesting to know the effect of ICT on writing in a bigger scale which will automatically have bigger effect size. Most of the research were done in a single class, or in a single educational institution. More research subjects, as well wider scope of study may have resulted in different conclusion than the previous studies. Previous studies also uncovered that ICT improved students' attitude towards writing using ICT but not towards writing per se. this means that students still have low attitude towards writing, this is a serious problem, since attitude towards writing is one of the important factors which affected the students writing achievement (Reid, 1993; Ismail, Hussin, \& Darus, 2012; Pamuji 2015). Therefore, it is imperative for researcher to further study the relationship between the use of ICT and students' attitude towards writing.

Another conclusion that we can draw from the previous study is that the results of the effectiveness of technology on writing achievement, especially when using Facebook, is still inconclusive. As found by Altunkaya \& Topuzkanamis (2018), Facebook does not have any effect of students' writing, in contrary to the result of Shih (2011) and Saad, Tahir, \& Primsuwan (2018) study which both concluded that Facebook improved students writing and students learning autonomy. More research results are needed before we can conclude that ICT really improves students' writing skill. This is important because writing teachers, by thinking critically and carefully about technology, can succeed in using to improve the educational spaces we live in (Hawisher \& Selfe, 1991). In improving students writing skill, we also have to take into account other variables which may improve or even hinder their writing learning, such as the students' culture. A study by Sayed (2010) provides an interesting result. As mentioned before, Sayed concluded that the use of Blog-based feedback is more effective and preferred by the Arabic students' due to its compatibility with the Arabic and Islamic culture. The Arabic and Islamic culture prefer indirect criticism, as face-to-face criticism is viewed as too direct and impolite thus less preferred by society. It is interesting to see whether Asian students' and teachers' perception of this cultural effect of Blog on writing, because Asia share similar indirect culture with the Arabic culture. The result of these researches may be used as the reasoning in using ICT as preferred teaching leaning aid due to its compatibility with the local culture of the students.

For future researches on ICT and Writing, going forward along the line set by the development of ICT technology is inevitable. Judging from the latest development in ICT based learning, the next field of research is most probably the Learning Management System. Learning Management System (LMS), also referred to as Course Management System (CMS) or Virtual Learning Environment (VLE), has evolved over decades of technological innovation to 
become a cornerstone of institutional instructional technology infrastructure (Rhode, Richter, Gowen, Miller, \& Wills, 2017). The development of LMS, especially the online type such as Moodle, Edmodo, Google Classroom, and Schoology, will change the landscape of learning. Naturally this will also bring changes for English learning including writing. The research into the use of LMS continuously increased over time. The focus of the research varies from understanding faculty use of the LMS (Rhode, Richter, Gowen, Miller, \& Wills, 2017), Students' and Staffs' perception on the use of LMS (Holmes \& Rodriguez, 2018), Students' use of the LMS (Rashida, Nawaz, Sameem, 2018), to English as Foreign Language students' acceptance to the use of Google Site as Course Management System in learning English (Gamble, 2018). Sooner or later, researcher will start investigating the relationship between LMS, writing and other variables.

In a country like Indonesia which consisted of so many different culture as well as divided by geographical condition, online LMS is the perfect answer for students and teachers alike. In English writing teaching and learning, the effectiveness of LMS can be studied using quasi-experimental design with control group. The control group will be the students taught with conventional classroom. Meanwhile the experimental group will be taught using the LSM Schoology, the result of the post-test will show whether the students taught with LSM achieve higher writing score compare to the students' taught in conventional classroom. This research can also use gender and students' writing performance as the covariates. The result of the study would contribute to the theoretical significance of LMS use in writing classroom and English class in general.

\section{CONCLUSION}

Information and communication technology has developed in fascinating manner, growing more sophisticated in a higher rate of speed since the invention of Web 1.0. The advancement of the Information and communication technology plays vital role in the teaching or writing especially in English Language teaching setting. However, despite the numerous research on ICT and ELT writing, there are still areas of research which have not been conclusively studied such as the effectiveness of Facebook on students' writing. likewise, researcher still have to study the effect of ICT use towards writing, since research results indicated that the use of ICT does not automatically improve students towards writing per se. Further research in this area should also study the effect, use, and acceptance of Learning Management System which has been the prevalent theme in education nowadays. More results are needed before we can conclusively say that Learning Management System is effective. Even if Learning Management System is proven to be effective, we still have to be able to pinpoint which features or what aspects contribute to the effectiveness of said Learning Management System. 


\section{REFERENCES}

Aghaei, S., Nematbakhsh, M.A., \& Farsani, H. K. (2012). Evolution of the World Wide Web: From Web 1.0 to Web 4.0. International Journal of Web \& Semantic Technology, 3(1), 1-10.

https://doi.org/10.5121/IJWEST.20 $\underline{12.3101}$

Altakhaineh, Abdel Rahman Mitib, and Majed Z. Al-Jallad. "The Use of Twitter and Facebook in Teaching Mechanics of Writing to ArabicSpeaking EFL Learners." International Journal of Emerging Technologies in Learning (iJET) 13.09 (2018): 4-14.

Altunkaya, H., \& Topuzkanamis, E. (2018). The Effect of Using Facebook in Writing Education on Writing Achievement, Attitude, Anxiety and Self-Efficacy Perception. Universal Journal of Educational Research, 6(10), 21332142.

Bangert-Drowns, R. L. (1993). The Word Processor as an Instructional Tool: A Meta-Analysis of Word Processing in Writing Instruction. Review of Educational Research, 63(1), 69-93.

Bax, S. (2003). CALL - past, present and future. System, 31(1), 13-28.

Campbell, A. P. (2003). Weblogs for Use with ESL Classes. The Internet TESL Journal, Vol. IX, No. 2.

Cooper, M. M., \& Selfe, C. L. (1990). Computer Conferences and Learning: Authority, Resistance, and Internally Persuasive Discourse. College English, 52(8), 847-869.
Dizon, G., \& Thanyawatpokin, B. (2018). Web 2.0 Tools in The EFL Classroom: Comparing The Effects of Facebook and Blogs On L2 Writing and Interaction. The EuroCALL Review, 26(1), 29-42.

Drexler, W., Dawson, K., \& Ferdig, R. E. (2007). Collaborative Blogging as A Means to Develop Elementary Expository Writing Skills. Electronic Journal for the Integration of Technology in Education, 6, 140160.

Ducate 1, L. C., \& Lomicka, L. L. (2008). Adventures in The Blogosphere: From Blog Readers to Blog Writers. Computer Assisted Language Learning, 21(1), 9-28.

Dudeney, G., \& Hockly, N. (2012). ICT in ELT: How Did We Get Here and Where Are We Going? ELT Journal, 66(4), 533-542.

Gamble, C. (2018). Exploring EFL University Students' Acceptance of E-learning Using TAM. Kwansei Gakuin University Humanities Review, 22, 23-37.

Godwin-Jones, R. (2003). Emerging Technologies: Blogs and Wikis: Environments for On-Line Collaboration. Language, Learning \& Technology, 7(2), 12-16.

Graham, S., \& Perin, D. (2007). Writing Next: Effective Strategies to Improve Writing of Adolescents in Middle and High Schools. A report to Carnegie Corporation of New York, Washington, DC: Alliance for Excellent Education. pp. 1-66. Accessed from https://www.carnegie.org/media/f iler public/3c/f5/3cf58727-34f4$\underline{\text { 4140-a014- }}$ 
723a00ac56f7/ccny report 2007

writing.pdf on December 52018.

Hawisher, G. E., \& Selfe, C. L. (1991). The

Rhetoric of Technology and The

Electronic Writing Class. College

Composition

and

Communication, 42(1), 55-65.

Holmes, K. A., \& Prieto-Rodriguez, E. (2018). Student and Staff Perceptions of a Learning Management System for Blended Learning in Teacher Education. Australian Journal of Teacher Education, 43(3), 21-34.

Ismail, N., Hussin, S., \& Darus, S. (2012). ESL Students' Attitude, Learning Problems, And Needs for Online Writing. GEMA Online® Journal of Language Studies, 12(4).

Ibrahim, S., Saad, S., Tahir, N. M., \& Primsuwan, P. (2018). Promoting Learners' Autonomy by Using Facebook to Enhance Students' Writing Skills.

MacArthur, C. A. (1988). The Impact of Computers On the Writing Process. Exceptional Children, 54(6), 536-542.

Olshtain, E. (2001). Functional Tasks for Mastering the Mechanics of Writing and Going Just Beyond. In M. Celce-Murcia (Ed.), Teaching English as A Second or Foreign Language (PP. 206-217), 3rd edition. USA: Heinle\& Heinle.

Pamuji, A. (2015). The Correlation Among Attitude, Reading Comprehension, and Writing Achievement of English Education Study Program Students of Sriwijaya University. Jurnal Adminika, 1(1).
Promnitz-Hayashi, L. (2011). A Learning Success Story Using Facebook. Studies in Self-Access Learning Journal, 2(4), 309-316.

Reid, J. M. (1993). Teaching ESL Writing. Englewood Cliffs, NJ: Prentice Hall Regents.

Rhode, J., Richter, S., Gowen, P., Miller, T., \& Wills, C. (2017). Understanding Faculty Use of the Learning Management System. Online Learning, 21(3), 68-86.

Robinson-Staveley, K., \& Cooper, J. (1990). The Use of Computers for Writing: Effects On an English Composition Class. Journal of Educational Computing Research, 6(1), 41-48.

Sayed, O. H. (2010). Developing Business Management Students' Persuasive Writing through BlogBased Peer-Feedback. English Language Teaching, 3(3), 54-66.

Sullivan, N., \& Pratt, E. (1996). A Comparative Study of Two ESL Writing Environments: A Computer-Assisted Classroom and A Traditional Oral Classroom. System, 24(4), 491-501.

Sullivan, N. (1993). Teaching Writing On a Computer Network. Tesol Journal, 3(1), 34-35.

Warschauer, M., \& Healey, D. (1998). Computers and Language Learning: An Overview. Language Teaching, 31(2), 57-71.

Zhang, D. (2009). The Application of Blog in English Writing. Accessed from https://www.repository.cam.ac.uk bitstream/handle/1810/255674/20 0901-article8.pdf?sequence $=1$ 